\title{
Recombinant methioninase (rMETase) is an effective therapeutic for BRAF-V600E-negative as well as -positive melanoma in patient-derived orthotopic xenograft (PDOX) mouse models
}

\author{
Kei Kawaguchi ${ }^{1,2,3}$, Kentaro Igarashi ${ }^{1,2}$, Shukuan $\mathrm{Li}^{1}$, Qinghong Han ${ }^{1}$, Yuying Tan ${ }^{1}$, \\ Kentaro Miyake ${ }^{1,2}$, Tasuku Kiyuna ${ }^{1,2}$, Masuyo Miyake ${ }^{1,2}$, Takashi Murakami ${ }^{1,2}$, \\ Bartosz Chmielowski ${ }^{4}$, Scott D. Nelson ${ }^{5}$, Tara A. Russell ${ }^{6}$, Sarah M. Dry ${ }^{5}$, Yunfeng \\ Li $^{5}$, Michiaki Unno ${ }^{3}$, Fritz C. Eilber ${ }^{6}$ and Robert M. Hoffman ${ }^{1,2}$ \\ ${ }^{1}$ AntiCancer, Inc., San Diego, CA, USA \\ ${ }^{2}$ Department of Surgery, University of California, San Diego, CA, USA \\ ${ }^{3}$ Department of Surgery, Graduate School of Medicine, Tohoku University, Sendai, Japan \\ ${ }^{4}$ Division of Hematology-Oncology, University of California, Los Angeles, CA, USA \\ ${ }^{5}$ Department of Pathology, University of California, Los Angeles, CA, USA \\ ${ }^{6}$ Division of Surgical Oncology, University of California, Los Angeles, CA, USA \\ Correspondence to: Robert M. Hoffman, email: all@anticancer.com \\ Fritz C. Eilber, email: fceilber@mednet.ucla.edu \\ Keywords: melanoma; recombinant methioninase; methionine dependence; BRAF-V600E mutation; PDOX \\ Received: October 12, $2017 \quad$ Accepted: November 19, $2017 \quad$ Published: December 12, 2017 \\ Copyright: Kawaguchi et al. This is an open-access article distributed under the terms of the Creative Commons Attribution License 3.0 \\ (CC BY 3.0), which permits unrestricted use, distribution, and reproduction in any medium, provided the original author and source \\ are credited.
}

\section{ABSTRACT}

Melanoma is a recalcitrant disease. Melanoma patients with the BRAF-V600E mutation have been treated with the drug vemurafenib (VEM) which targets this mutation. However, we previously showed that VEM is not very effective against a BRAF-V600E melanoma mutant in a patient-derived orthotopic xenograft (PDOX) model. In contrast, we demonstrated that recombinant methioninase (rMETase) which targets the general metabolic defect in cancer of methionine dependence, was effective against the BRAF-V600E mutant melanoma PDOX model. In the present study, we demonstrate that rMETase is effective against a BRAF-V600E-negative melanoma PDOX which we established. Forty BRAF-V600E-negative melanoma PDOX mouse models were randomized into four groups of 10 mice each: untreated control $(n=10)$; temozolomide (TEM) $(25 \mathrm{mg} / \mathrm{kg}$, p.o., 14 consecutive days, $n=10)$; rMETase (100 units, i.p., 14 consecutive days, $n=10$ ); TEM + rMETase (TEM: 25 mg/ kg, p.o., rMETase: 100 units, i.p., 14 consecutive days, $n=10$ ). All treatments inhibited tumor growth compared to untreated control (TEM: $p=0.0003$, rMETase: $p=0.0006$, TEM/ rMETase: $p=\mathbf{0 . 0 0 0 2}$ ) on day 14 after initiation. Combination therapy of TEM and rMETase was significantly more effective than either mono-therapy (TEM: $p=0.0113$, rMETase: $p=0.0173$ ). The present study shows that TEM combined with rMETase is effective for BRAF-V600E-negative melanoma PDOX similar to the BRAF-V600Epositive mutation melanoma. These results suggest rMETase in combination with firstline chemotherapy can be highly effective in both BRAF-V600E-negative as well as BRAF-V600E-positive melanoma and has clinical potential for this recalcitrant disease. 


\section{INTRODUCTION}

Melanoma is a recalcitrant cancer [1] with no cure for stage III and IV due to many factors including drug resistance, tumor heterogeneity and an immunesuppressed tumor microenvironment [2].

Temozolomide (TEM), an alkylating agent, is first-line chemotherapy for melanoma but with limited efficacy [1-5].

An excessive requirement for methionine (MET) termed MET dependence, appears to be a general metabolic defect in cancer. MET restriction therapy, using recombinant methioninase (rMETase), sensitized brain tumors to TEM in xenografts in nude mice [6]. In a previous study, we tested a patient-derived orthotopic xenograft (PDOX) nude mouse model of BRAF V600E-mutant melanoma and observed the efficacy of rMETase [7].

In the present study, we established a PDOX nude mouse model with a BRAF-V600E-negative melanoma from a patient. We evaluated the efficacy of rMETase and rMETase in combination with TEM on the BRAF-V600Enegative melanoma.

\section{RESULTS AND DISCUSSION}

Temozolomide (TEM) $(p=0.0003)$, rMETase $(p=0.0006)$ and the combination of TEM/rMETase $(p=0.0002)$ inhibited tumor growth in the BRAFV600E-negative PDOX, as measured on day 14 after initiation. The combination of TEM and rMETase was significantly more effective than TEM $(p=0.0113)$ and $\operatorname{rMETase}(p=0.0173)$ alone. There was no significant difference between TEM and rMETase alone $(p=0.4274)$ (Figure 1).
Post-treatment MET levels in tumors treated with rMETase alone $(p=0.0009)$ or in combination with TEM $(p=0.0006)$ were significantly decreased compared to the untreated control (Figure 2), suggesting the lowering of tumor MET levels by rMETase is the mechanism of inhibition.

These results showed that this BRAF-V600Enegative melanoma PDOX is MET dependent and rMETase suppresses its growth, especially in combination with first-line chemotherapy TEM.

Slight body weight loss was observed only in the combination treatment group, however there were no significant difference in body weight between any group (Figure 3). There were no animal deaths in any group.

Histologically, the untreated control tumor was mainly comprised of viable cells. The viable cancer cells of the untreated control specimen and the treated specimens had a similar appearance. The cancer cells display epithelioid to slightly spindly morphology, and contain moderate amounts of eosinophilic cytoplasm, with some cytoplasmic vacuolization present. Nuclei are moderately pleomorphic with 1 to 2 prominent nucleoli. Mitotic activity was present. The same slight degree of necrosis was observed in tumors treated with TEM and rMETase. In contrast, tumors treated with the combination of TEM and rMETase showed extensive necrosis (Figure 4).

TEM has been widely used as standard chemotherapy for BRAF-V600E-negative melanoma [1-5]. In this study, TEM inhibited tumor growth to a certain extent. TEM in combination with rMETase was significantly more effective than TEM alone, similar to our previous study for VEM resistant BRAF-V600E-positive melanoma [7].

The present study has important implications since this is the first report that TEM combined with rMETase

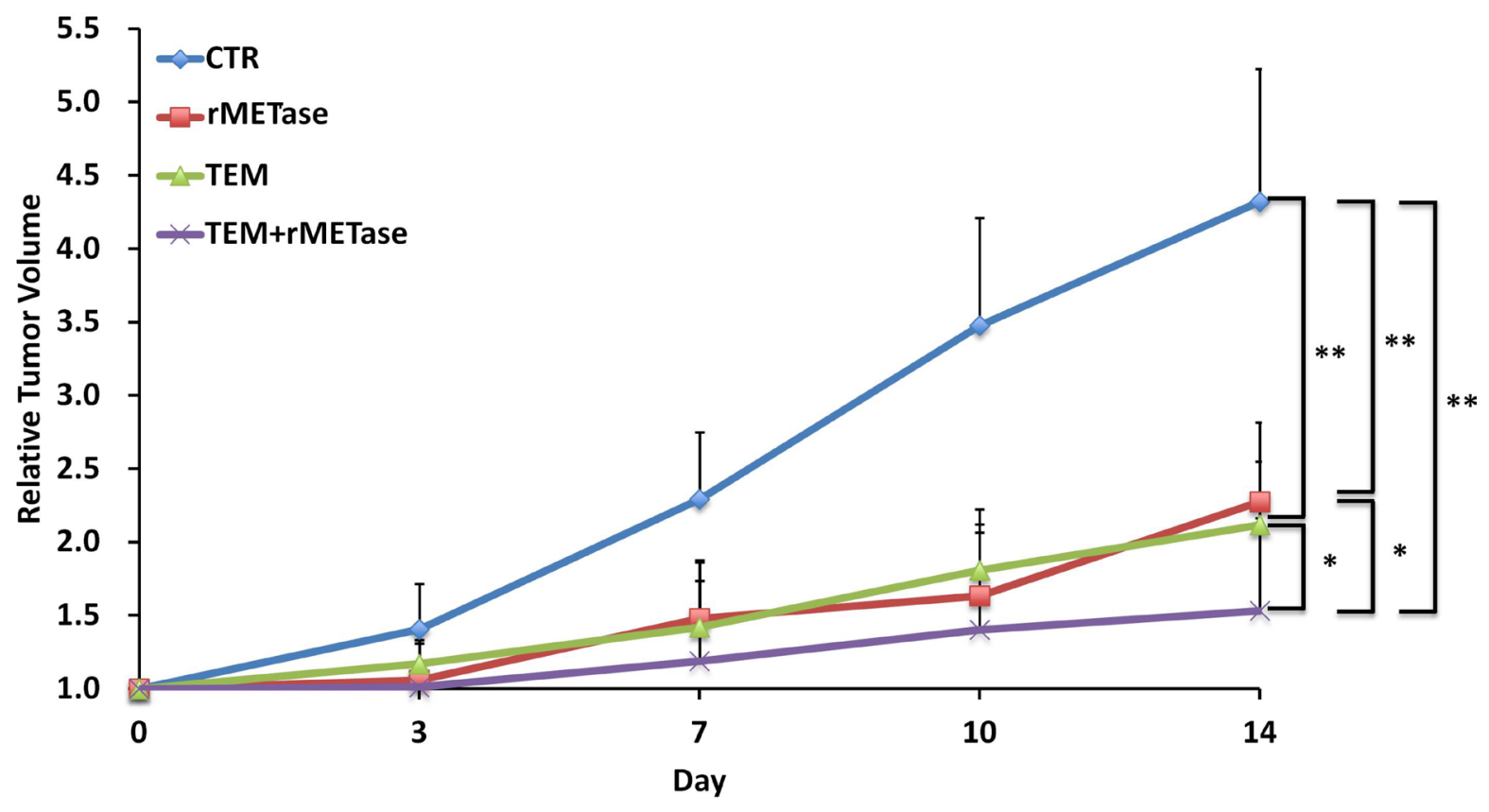

Figure 1: Quantitative efficacy of chemotherapy on the BRAF-V600E-negative PDOX. Line graphs show relative tumor volume at each point relative to the initial tumor volume for each treatment and control group. ${ }^{*} p<0.02 ;{ }^{* *} p<0.01$. Error bars: \pm SD. 
is effective treatment for melanoma regardless of BRAFV600E mutation status.

Effective individualized therapy requires matching the cancer patient with an effective drug. Toward this goal, our laboratory pioneered the patient-derived orthotopic xenograft (PDOX) nude mouse model with the technique of surgical orthotopic implantation (SOI), including breast [8], ovarian [9], lung [10], cervical [11, 12], colon [13-15], stomach [16], pancreatic [17-21], melanoma [22-26], and sarcoma [27-36]. The PDOX model, developed by our laboratory over the past 30 years, has many advantages over subcutaneous-transplant models which are growing ectopically under the skin [37]. The PDOX model enables precise, individualized therapy, especially for recalcitrant diseases such as melanoma [23] by

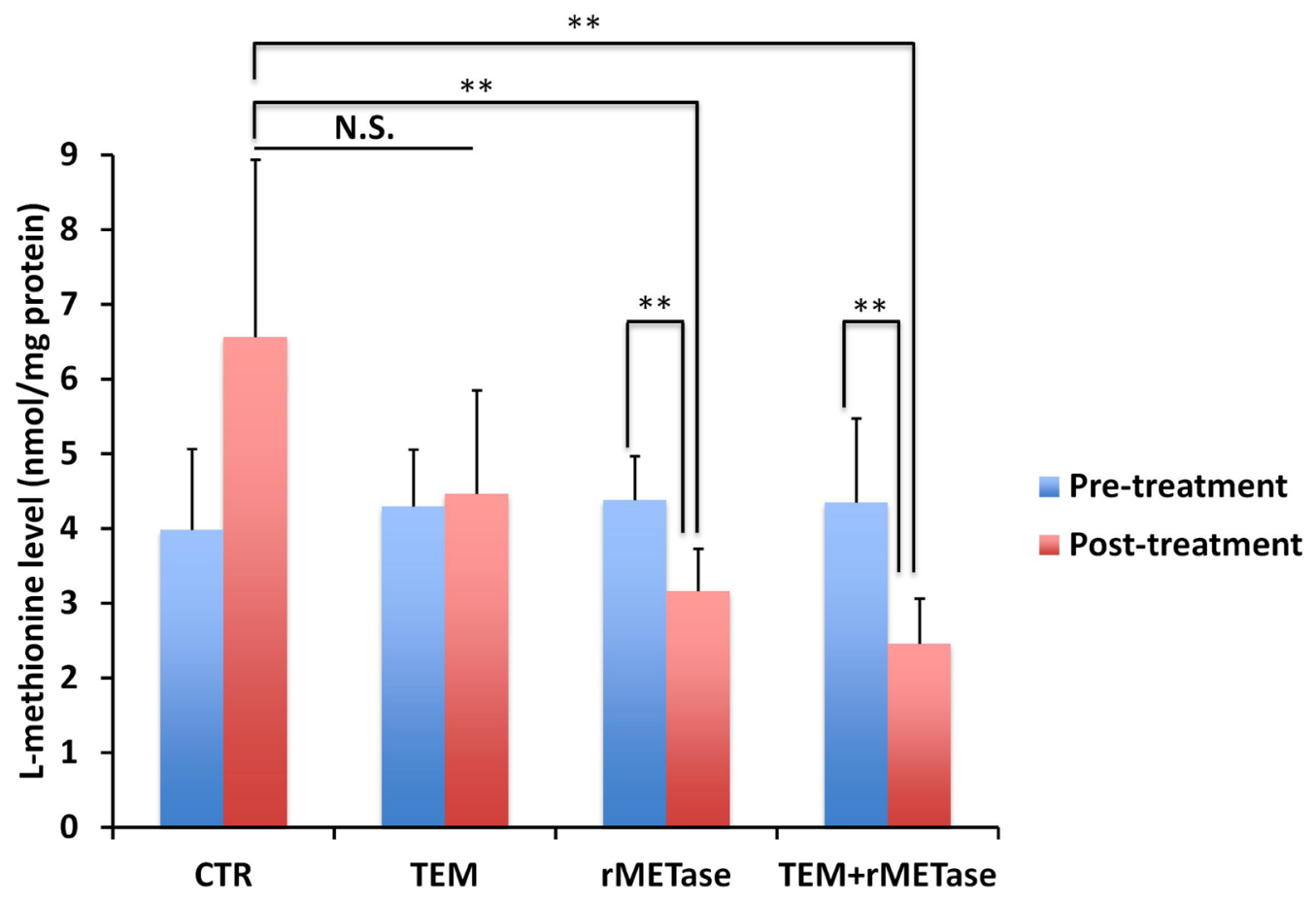

Figure 2: Intra-tumor MET levels. Bar graphs show MET level in each treatment or control group at pre- and post-treatment time points. ${ }^{* *} p<0.01$.

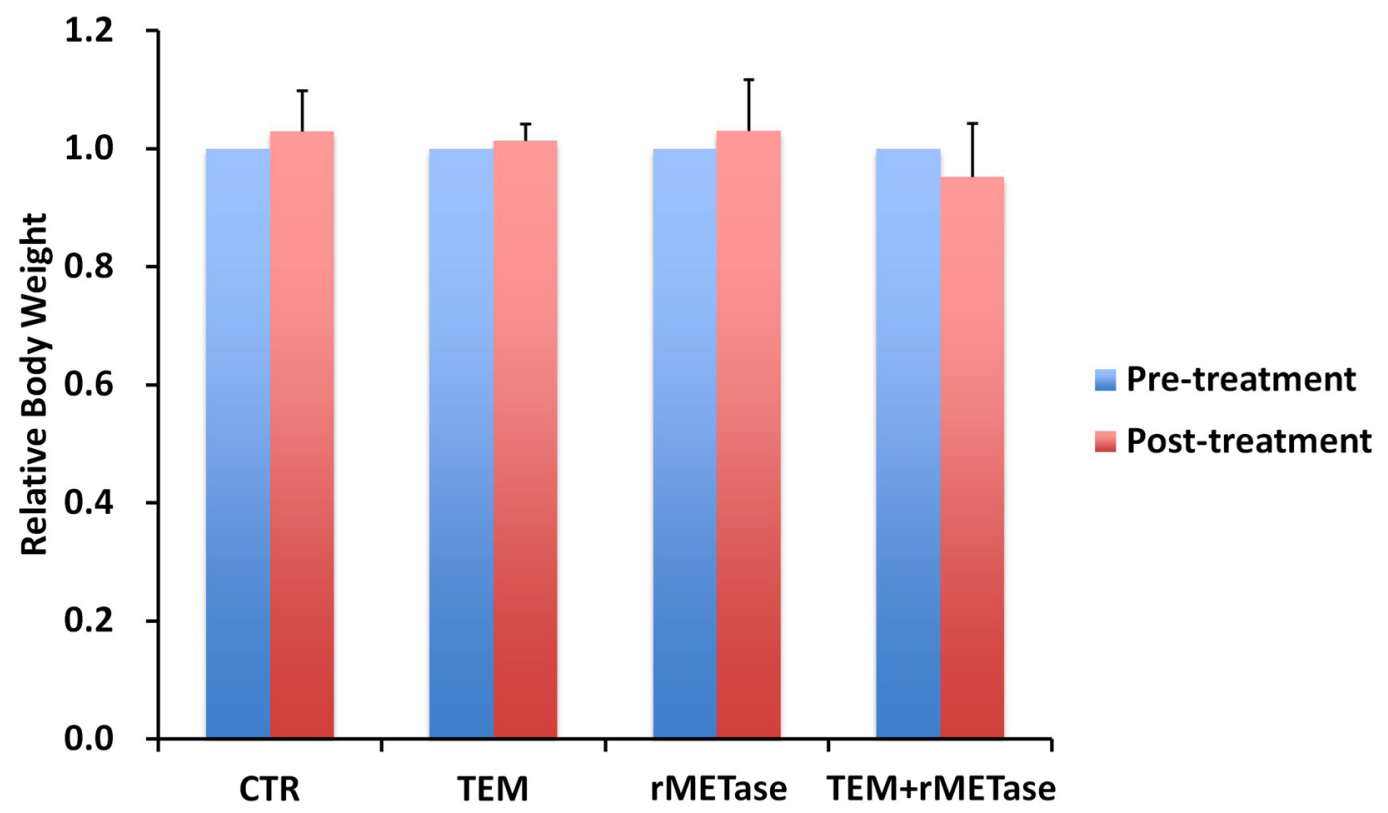

Figure 3: Mouse body weight. Bar graphs show mouse body weight in each treatment or control group at pre- and post-treatment time points. 
matching the patient tumor to an effective drug identified with the PDOX models.

Methionine dependence is due to excess use of methionine for aberrant transmethylation reactions $[38,39]$. The elevated methionine use in cancer cells has been termed the "Hoffman effect" $[29,39]$ analogous to the "Warburg effect" [40] for elevated aerobic glucose use in cancer. The excessive and aberrant use of methionine in cancer is observed in $\left[{ }^{11} \mathrm{C}\right]$ methionine PET imaging, where high uptake of $\left[{ }^{11} \mathrm{C}\right]$ methionine results in a very strong and selective tumor signal compared to normal tissue background for brain and other cancers [39]. In a comparison of MET-PET and fluorodeoxyglucose (FDG)PET, MET-PET was found to be superior for glioma [4146] suggesting that cancer may have a greater abnormal requirement for methionine than glucose [39].

Cell lines derived from various cancer types including liver, pancreatic ovarian, submaxillary, brain, lung, bladder, prostate, breast, kidney, cervical, colon, fibrosarcoma, osteosarcoma, rhabdomyosarcoma, leiomyosarcoma, neuroblastoma, glioblastoma and melanoma were shown to be methionine dependent in contrast to normal cell lines. Human patient tumors, including tumors of the colon, breast, ovary, prostate, and a melanoma, were also found to be methionine dependent in Gelfoam ${ }^{\circledR}$ histoculture $[39,47]$.
We reported recently on efficacy of rMETase against Ewing's sarcoma in a PDOX model. rMETase effectively reduced tumor growth compared to untreated control [29]. We also recently reported that TEM combined with rMETase could strongly inhibit tumor growth of BRAFV600E-positive melanoma PDOX [29]. The occurrence of methionine dependence among many diverse cancer types suggests that methionine dependence is a general phenomena in cancer [39].

Previously-developed concepts and strategies of highly-selective tumor targeting can take advantage of molecular targeting of tumors, including tissue-selective therapy which focuses on unique differences between normal and tumor tissues [48-53].

\section{CONCLUSIONS}

The present study has demonstrated the efficacy of rMETase and the combination of rMETase and TEM on a BRAF-V600E-negative melanoma PDOX model. These results sugest that both BRAF-V600E-negative as well as -positive melanoma are sensitive to rMETase. Further PDOX experiments will determine the general efficacy of rMETase on melanoma as a prelude to its clinical development for this recalcitrant disease.
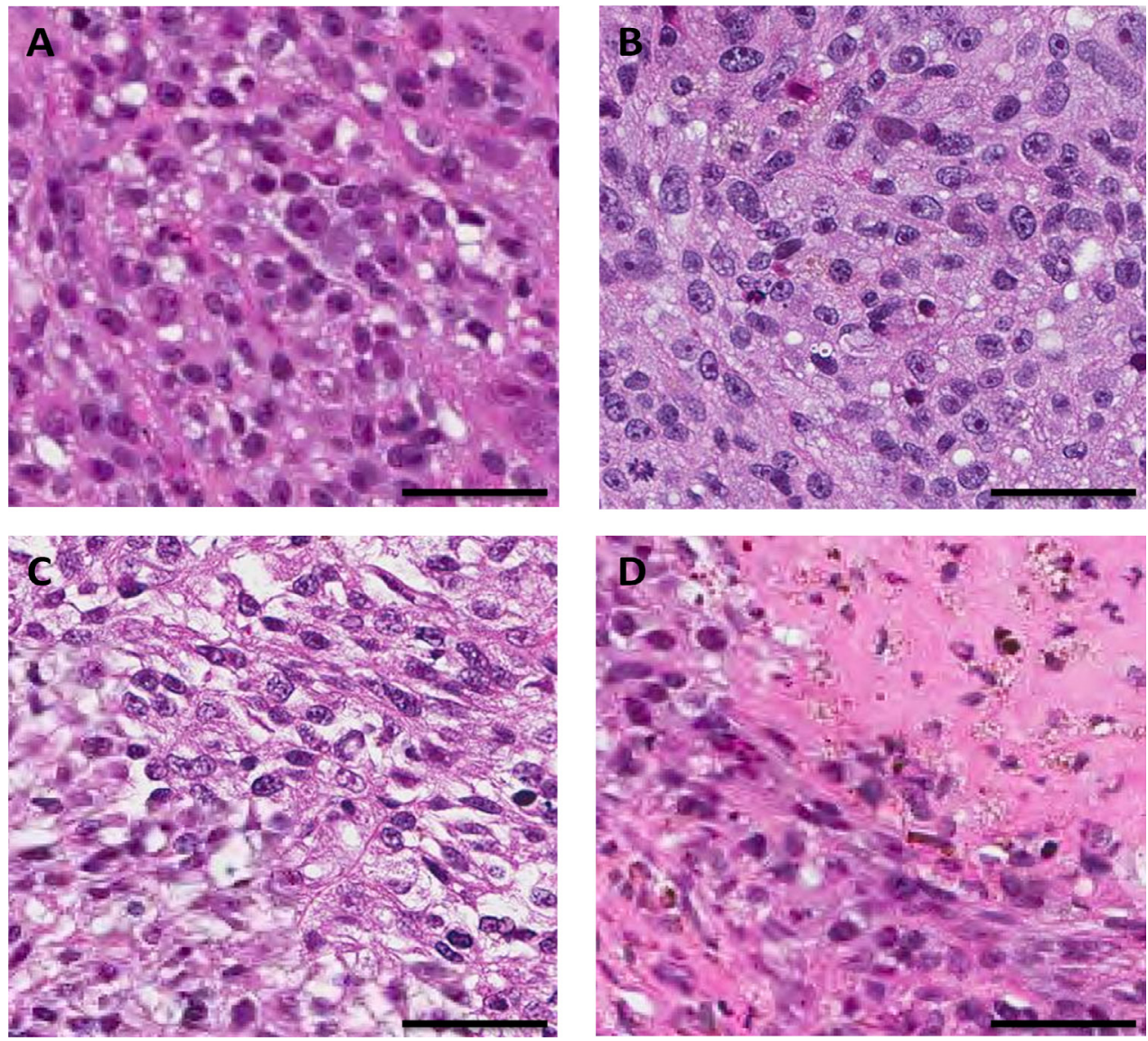

Figure 4: Tumor histology. (A) Untreated control. (B) TEM treated. (C) rMETase treated. (D) TEM/rMETase treated. Scale bars: $50 \mu \mathrm{m}$. 
Both classical and novel forms of vitamin D have shown efficacy against melanoma progression and management, including in the adjuvant setting [54, 55]. Future experiments will evaluate rMETase along with classical and novel forms of vitamin D. We recently reviewed the establishment and properties of PDOX models of melanoma [56].

\section{MATERIALS AND METHODS}

\section{Mice}

Athymic $n u / n u$ nude mice (AntiCancer Inc., San Diego, CA), 4-6 weeks old, were used in this study. Mice were housed in a barrier facility on a high efficacy particulate arrestance (HEPA)-filtered rack under standard conditions of 12-hour light/dark cycles. The animals were fed an autoclaved laboratory rodent diet. All animal studies were conducted in accordance with the principles and procedures outlined in the National Institutes of Health Guide for the Care and Use of Animals under Assurance Number A3873-1. All mouse surgical procedures and imaging were performed with the animals anesthetized by subcutaneous injection of a ketamine mixture $(0.02 \mathrm{ml}$ solution of $20 \mathrm{mg} / \mathrm{kg}$ ketamine, $15.2 \mathrm{mg} / \mathrm{kg}$ xylazine, and $0.48 \mathrm{mg} / \mathrm{kg}$ acepromazine maleate). The response of animals during surgery was monitored to ensure adequate depth of anesthesia. The animals were observed on a daily basis and humanely sacrificed by $\mathrm{CO}_{2}$ inhalation if they met the following humane endpoint criteria: severe tumor burden (more than $20 \mathrm{~mm}$ in diameter), prostration, significant body weight loss, difficulty breathing, rotational motion and body temperature drop [7].

\section{Patient-derived tumor}

A patient diagnosed with a BRAF-600E-negative melanoma of the abdominal wall was resected in the Department of Surgery, University of California, Los Angels (UCLA). Written informed consent was provided by the patient, and the Institutional Review Board (IRB\#10-001857) of UCLA approved that the patient's resected melanoma could be used for the present study. The tumor was designated at PDOX063.

\section{Establishment of PDOX models of melanoma by surgical orthotopic implantation (SOI)}

A fresh sample of the melanoma of the patient was obtained and transported immediately to the laboratory at AntiCancer, Inc., on wet ice. The sample was cut into 5-mm fragments and implanted subcutaneously in nude mice. After three weeks, the subcutaneously-implanted tumors grew to more than $10 \mathrm{~mm}$ in diameter. The subcutaneouslygrown tumors were then harvested and cut into small fragments $\left(3 \mathrm{~mm}^{3}\right)$. After nude mice were anesthetized with the ketamine solution described above, a 5-mm skin incision was made on the abdominal wall, which was split to make space for the melanoma tissue fragment. A single tumor fragment was implanted orthotopically into the space to establish the PDOX model. The wound was closed with a 6-0 nylon suture (Ethilon, Ethicon, Inc., NJ, USA) [23, 24].

\section{Recombinant methionase (rMETase) production}

Recombinant L-metionine $\alpha$-deamino- $\gamma$-mercaptomethane lyase (recombinant methioninase, [rMETase]) [EC 4.4.1.11] from Pseudomonas putida has been previously cloned and was produced in Escherichia coli (AntiCancer, Inc., San Diego, CA). rMETase is a homotetrameric PLP enzyme of 172-kDa molecular mass [57].

\section{Treatment study design in the PDOX model of melanoma}

PDOX mouse models of BRAF-V600E-negative melanoma were randomized into four groups of 10 mice each: untreated control $(n=10)$; TEM $(25 \mathrm{mg} / \mathrm{kg}$, oral [p.o.], 14 consecutive days, $n=10$ ); rMETase (100 units, intraperitoneal [i.p.], 14 consecutive days, $n=10)$; TEM + rMETase (TEM: $25 \mathrm{mg} / \mathrm{kg}$, p.o., rMETase: 100 units, i.p., 14 consecutive days, $n=10$ ). Tumor length and width were measured twice a week. Tumor volume was calculated with the following formula: Tumor volume $\left(\mathrm{mm}^{3}\right)=$ length $(\mathrm{mm}) \times$ width $(\mathrm{mm}) \times$ width $(\mathrm{mm}) \times 1 / 2$. Data are presented as mean $\pm \mathrm{SD}$. The tumor volume ratio is defined at the tumor volume at each point relative to pre-treatment tumor volume.

\section{Intra-tumor MET level analysis}

Each tumor, untreated or treated, was sonicated for 30 seconds on ice and centrifuged at 12,000 rpm for 10 minutes. Supernatants were collected and protein levels were measured using the Coomassie Protein Assay Kit (Thermo Scientific, Rockford, IL). Protein levels were calculated from the standard curve obtained by protein standard, bovine serum albumin (BSA). MET levels were determined with an HPLC procedure described previously $[29,58]$. Standardized MET levels were calculated using the following formula: MET level (nmol/mg protein $)=$ MET level (nmol/ml) / protein level (mg protein/ml) [7].

\section{Histological examination}

Fresh tumor samples, both untreated and treated, were fixed in $10 \%$ formalin and embedded in paraffin before sectioning and staining. Tissue sections $(5 \mu \mathrm{m})$ were deparaffinized in xylene and rehydrated in an ethanol series. Hematoxylin and eosin (H\&E) staining was performed according to standard protocols. Histological examination was performed with a BHS System 
Microscope (Olympus Corporation, Tokyo, Japan). Images were acquired with INFINITY ANALYZE software (Lumenera Corporation, Ottawa, Canada) [23-26].

\section{Statistical analysis}

JMP version 11.0 was used for all statistical analyses. Significant differences for continuous variables were determined using the Mann-Whitney $U$ test. Line graphs express average values and error bars show SD. A probability value of $P \leq 0.05$ was considered statistically significant [7].

\section{DEDICATION}

This paper is dedicated to the memory of A. R. Moossa, M.D., and Sun Lee, M.D.

\section{CONFLICTS OF INTEREST}

The authors declare that there are no potential conflicts of interest.

\section{REFERENCES}

1. Chapman PB, Hauschild A, Robert C, Haanen JB, Ascierto P, Larkin J, Dummer R, Garbe C, Testori A, Maio M, Hogg D, Lorigan P, Lebbe C, et al. Improved survival with vemurafenib in melanoma with BRAF V600E mutation. N Engl J Med. 2011; 364:2507-2516.

2. Flaherty LE, Othus M, Atkins MB, Tuthill RJ, Thompson JA, Vetto JT, Haluska FG, Pappo AS, Sosman JA, Redman BG, Moon J, Ribas A, Kirkwood JM, et al. Southwest Oncology Group S0008: a phase III trial of high-dose interferon Alfa- $2 \mathrm{~b}$ versus cisplatin, vinblastine, and dacarbazine, plus interleukin-2 and interferon in patients with high-risk melanoma - an intergroup study of cancer and leukemia Group B, Children's Oncology Group, Eastern Cooperative Oncology Group, and Southwest Oncology Group. J Clin Oncol. 2014; 32:3771-3778.

3. Tang H, Wang Y, Chlewicki LK, Zhang Y, Guo J, Liang W, Wang J, Wang X, Fu YX. Facilitating T Cell infiltration in tumor microenvironment overcomes resistance to PD-L1 blockade. Cancer Cell. 2016; 29:285-296.

4. Brozyna AA, Jóźwicki W, Roszkowski K, Filipiak J, Slominski AT. Melanin content in melanoma metastases affects the outcome of radiotherapy. Oncotarget. 2016; 7:17844-17853. https://doi.org/10.18632/oncotarget.7528.

5. Slominski AT, Carlson JA. Melanoma resistance: a bright future for academicians and a challenge for patient advocates. Mayo Clin Proc. 2014; 89:429-433.

6. Kokkinakis DM, Hoffman RM, Frenkel EP, Wick JB, Han Q, Xu M, Tan Y, Schold SC. Synergy between methionine stress and chemotherapy in the treatment of brain tumor xenografts in athymic mice. Cancer Res. 2001; 61:4017-4023.

7. Kawaguchi K, Igarashi K, Li S, Han Q, Tan Y, Kiyuna T, Miyake K, Murakami T, Chmielowski B, Nelson SD, Russell TA, Dry SM, Li Y, et al. Combination treatment with recombinant methioninase enables temozolomide to arrest a BRAF V600E melanoma in a patient-derived orthotopic xenograft (PDOX) mouse model. Oncotarget. 2017; 8:85516-85525. https://doi.org/10.18632/oncotarget.20231.

8. Fu X, Le P, Hoffman RM. A metastatic-orthotopic transplant nude-mouse model of human patient breast cancer. Anticancer Res. 1993; 13:901-904.

9. $\mathrm{Fu} \mathrm{X}$, Hoffman RM. Human ovarian carcinoma metastatic models constructed in nude mice by orthotopic transplantation of histologically-intact patient specimens. Anticancer Res. 1993; 13:283-286.

10. Wang X, Fu X, Hoffman RM. A new patient-like metastatic model of human lung cancer constructed orthotopically with intact tissue via thoracotomy in immunodeficient mice. Int J Cancer. 1992; 51:992-995.

11. Hiroshima Y, Zhang Y, Zhang N, Maawy A, Mii S, Yamamoto M, Uehara F, Miwa S, Yano S, Murakami T, Momiyama M, Chishima T, Tanaka K, et al. Establishment of a patient-derived orthotopic xenograph (PDOX) model of HER-2-positive cervical cancer expressing the clinical metastatic pattern. PLos One. 2015; 10:e0117417.

12. Murakami $T$, Kiyuna $T$, Kawaguchi $\mathrm{K}$, Igarashi $\mathrm{K}$, Singh AS, Hiroshima Y, Zhang Y, Zhao M, Miyake K, Nelson SD, Dry SM, Li Y, DeLong J, et al. The irony of highly-effective bacterial therapy of a patient-derived orthotopic xenograft (PDOX) model of Ewing's sarcoma, which was blocked by Ewing himself 80 years ago. Cell Cycle. 2017; 16:1046-1052.

13. Hiroshima Y, Maawy A, Metildi CA, Zhang Y, Uehara F, Miwa S, Yano S, Sato S, Murakami T, Momiyama M, Chishima T, Tanaka K, Bouvet M, et al. Successful fluorescence-guided surgery on human colon cancer patient-derived orthotopic xenograft mouse models using a fluorophore-conjugated anti-CEA antibody and a portable imaging system. J Laparoendosc Adv Surg Tech A. 2014; 24:241-247.

14. Fu X, Besterman JM, Monosov A, Hoffman RM. Models of human metastatic colon cancer in nude mice orthotopically constructed by using histologically intact patient specimens. Proc Natl Acad Sci USA. 1991; 88:9345-9349.

15. Metildi CA, Kaushal S, Luiken GA, Talamini MA, Hoffman RM, Bouvet M. Fluorescently-labeled chimeric anti-CEA antibody improves detection and resection of human colon cancer in a patient-derived orthotopic xenograft (PDOX) nude mouse model. J Surg Oncol. 2014; 109:451-458.

16. Furukawa $T$, Kubota $T$, Watanabe $M$, Kitajima $M$, Hoffman RM. Orthotopic transplantation of histologically intact clinical specimens of stomach cancer to nude mice: 
correlation of metastatic sites in mouse and individual patient donors. Int J Cancer. 1993; 53:608-612.

17. Fu X, Guadagni F, Hoffman RM. A metastatic nudemouse model of human pancreatic cancer constructed orthotopically with histologically intact patient specimens. Proc Natl Acad Sci USA. 1992; 89:5645-5649.

18. Kawaguchi K, Igarashi K, Murakami T, Kiyuna T, Lwin TM, Hwang HK, Delong JC, Clary BM, Bouvet M, Unno M, Hoffman RM. MEK inhibitors cobimetinib and trametinib, regressed a gemcitabine-resistant pancreatic cancer patient-derived orthotopic xenograft (PDOX). Oncotarget. 2017; 8:47490-47496. https://doi.org/10.18632/ oncotarget.17667.

19. Hiroshima Y, Zhang Y, Murakami T, Maawy A, Miwa S, Yamamoto M, Yano S, Sato S, Momiyama M, Mori R, Matsuyama R, Chishima T, Tanaka K, et al. Efficacy of tumor-targeting Salmonella typhimurium A1-R in combination with anti-angiogenesis therapy on a pancreatic cancer patient-derived orthotopic xenograph (PDOX) and cell line mouse models. Oncotarget. 2014; 5:12346-12357. https://doi.org/10.18632/oncotarget.2641.

20. Hiroshima Y, Maawy A, Zhang Y, Murakami T, Momiyama M, Mori R, Matsuyama R, Katz MH, Fleming JB, Chishima T, Tanaka K, Ichikawa Y, Endo I, et al. Metastatic recurrence in a pancreatic cancer patient derived orthotopic xenograft (PDOX) nude mouse model is inhibited by neoadjuvant chemotherapy in combination with fluorescence-guided surgery with an anti-CA 19-9-conjugated fluorophore. PLos One. 2014; 9:e114310.

21. Hiroshima Y, Maawy AA, Katz MH, Fleming JB, Bouvet M, Endo I, Hoffman RM. Selective efficacy of zoledronic acid on metastasis in a patient-derived orthotopic xenograph (PDOX) nude-mouse model of human pancreatic cancer. J Surg Oncol. 2015; 111:311-315.

22. Yamamoto M, Zhao M, Hiroshima Y, Zhang Y, Shurell E, Eilber FC, Bouvet M, Noda M, Hoffman RM. Efficacy of tumor-targeting Salmonella typhimurium A1-R on a melanoma patient-derived orthotopic xenograft (PDOX) nude-mouse model. PLoS One. 2016; 11:e0160882.

23. Kawaguchi K, Murakami T, Chmielowski B, Igarashi K, Kiyuna T, Unno M, Nelson SD, Russell TA, Dry SM, Li Y, Eilber FC, Hoffman RM. Vemurafenib-resistant BRAF-V600E mutated melanoma is regressed by MEK targeting drug trametinib, but not cobimetinib in a patientderived orthotopic xenograft (PDOX) mouse model. Oncotarget. 2016; 7:71737-71743. https://doi.org/10.18632/ oncotarget.12328.

24. Kawaguchi K, Igarashi K, Murakami T, Chmiewloski B, Kiyuna T, Zhao M, Zhang Y, Singh A, Unno M, Nelson SD, Russell TA, Dry SM, Li Y, et al. Tumor-targeting Salmonella typhimurium A1-R combined with Temozolomide regresses malignant melanoma with a BRAF-V600 mutation in a patient-derived orthotopic xenograft (PDOX) model. Oncotarget. 2016; 7:85929-85936. https://doi.org/10.18632/ oncotarget.13231.
25. Kawaguchi K, Igarashi $K$, Murakami T, Kiyuna $T$, Zhao M, Zhang Y, Nelson SD, Russell TA, Dry SM, Singh AS, Chmielowski B, Li Y, Unno M, et al. Salmonella typhimurium A1-R targeting of a chemotherapy resistant BRAF-V600E melanoma in a patient-derived orthotopic xenograft (PDOX) model is enhanced in combination with either vemurafenib or temozlomide. Cell Cycle. 2017; 16:1288-1294.

26. Kawaguchi K, Igarashi K, Murakami T, Zhao M, Zhang Y, Chmielowski B, Kiyuna T, Nelson SD, Russell TA, Dry SM, Li Y, Unno M, Eilber FC, et al. Tumor-targeting Salmonella typhimurium A1-R sensitizes melanoma with a BRAF-V600E mutation to vemurafenib in a patient-derived orthotopic xenograft (PDOX) nude mouse model. J Cell Biochem. 2017; 118:2314-2319.

27. Murakami T, Singh AS, Kiyuna T, Dry SM, Li Y, James AW, Igarashi K, Kawaguchi K, DeLong JC, Zhang Y, Hiroshima Y, Russell T, Eckardt MA, et al. Effective molecular targeting of CDK4/6 and IGF-1R in a rare FUS-ERG fusion CDKN2Adeletion doxorubicin-resistant Ewing's sarcoma patientderived orthotopic xenograft (PDOX) nude-mouse model. Oncotarget. 2016; 7:47556-47564. https://doi.org/10.18632/ oncotarget.9879.

28. Murakami T, DeLong J, Eilber FC, Zhao M, Zhang Y, Zhang N, Singh A, Russell T, Deng S, Reynoso J, Quan C, Hiroshima Y, Matsuyama R, et al. Tumor-targeting Salmonella typhimurium A1-R in combination with doxorubicin eradicate soft tissue sarcoma in a patient-derived orthotopic xenograft PDOX model. Oncotarget. 2016; 7:12783-12790. https://doi.org/10.18632/oncotarget.7226.

29. Murakami T, Li S, Han Q, Tan Y, Kiyuna T, Igarashi K, Kawaguchi K, Hwang HK, Miyaki K, Singh AS, Nelson SD, Dry SM, Li Y, et al. Recombinant methioninase effectively targets a Ewing's sarcoma in a patient-derived orthotopic xenograft (PDOX) nude-mouse model. Oncotarget. 2017; 8:35630-35638. https://doi.org/10.18632/oncotarget.15823.

30. Igarashi $\mathrm{K}$, Kawaguchi $\mathrm{K}$, Murakami $\mathrm{T}$, Kiyuna $\mathrm{T}$, Miyake K, Singh A, Nelson SD, Dry SM, Li Y, Yamamoto N, Hayashi K, Kimura H, Miwa S, et al. High efficacy of pazopanib on an undifferentiated spindle-cell sarcoma resistant to first-line therapy is identified with a patientderived orthotopic xenograft (PDOX) nude mouse model. J Cell Biochem. 2017; 118:2739-2743.

31. Igarashi K, Kawaguchi K, Kiyuna T, Murakami T, Miwa S, Nelson SD, Dry SM, Li Y, Singh A, Kimura H, Hayashi K, Yamamoto N, Tsuchiya H, et al. Temozolomide combined with irinotecan caused regression in an adult pleomorphic rhabdomyosarcoma patient-derived orthotopic xenograft (PDOX) nude-mouse model. Oncotarget. 2017; 8:7587475880. https://doi.org/10.18632/oncotarget.16548.

32. Igarashi K, Kawaguchi K, Kiyuna T, Murakami T, Miwa S, Nelson SD, Dry SM, Li Y, Singh A, Kimura H, Hayashi K, Yamamoto N, Tsuchiya H, et al. Patient-derived orthotopic xenograft (PDOX) mouse model of adult 
rhabdomyosarcoma invades and recurs after resection in contrast to the subcutaneous ectopic model. Cell Cycle. 2017; 16:91-94.

33. Igarashi $\mathrm{K}$, Kawaguchi $\mathrm{K}$, Murakami $\mathrm{T}$, Kiyuna $\mathrm{T}$, Miyake K, Nelson SD, Dry SM, Li Y, Yanagawa J, Russell TA, Singh AS, Yamamoto N, Hayashi K, et al. Intra-arterial administration of tumor-targeting Salmonella typhimurium A1-R regresses a cisplatin-resistant relapsed osteosarcoma in a patient-derived orthotopic xenograft (PDOX) mouse model. Cell Cycle. 2017; 16:1164-1170.

34. Hiroshima Y, Zhang Y, Zhang N, Uehara F, Maawy A, Murakami T, Mii S, Yamamoto M, Miwa S, Yano S, Momiyama M, Mori R, Matsuyama R, et al. Patient-derived orthotopic xenograft (PDOX) nude mouse model of softtissue sarcoma more closely mimics the patient behavior in contrast to the subcutaneous ectopic model. Anticancer Res. 2015; 35:697-701.

35. Kawaguchi K, Igarashi $\mathrm{K}$, Murakami $\mathrm{T}$, Kiyuna $\mathrm{T}$, Nelson SD, Dry SM, Li Y, Russell TA, Singh AS, Chmielowski B, Unno M, Eilber FC, Hoffman RM. Combination of gemcitabine and docetaxel regresses both gastric leiomyosarcoma proliferation and invasion in an imageable patient-derived orthotopic xenograft (iPDOX) model. Cell Cycle. 2017; 16:1063-1069.

36. Kiyuna T, Murakami T, Tome Y, Kawaguchi K, Igarashi K, Zhang Y, Zhao M, Li Y, Bouvet M, Kanaya F, Singh A, Dry S, Eilber FC, et al. High efficacy of tumor-targeting Salmonella typhimurium A1-R on a doxorubicin- and dactolisib-resistant follicular dendritic-cell sarcoma in a patient-derived orthotopic xenograft PDOX nude mouse model. Oncotarget. 2016; 7:33046-33054. https://doi. org/10.18632/oncotarget.8848.

37. Hoffman RM. Patient-derived orthotopic xenografts: better mimic of metastasis than subcutaneous xenografts. Nat Rev Cancer. 2015; 15:451-452.

38. Stern PH, Hoffman RM. Elevated overall rates of transmethylation in cell lines from diverse human tumors. In Vitro - Rapid Commun in Cell Biology. 1984; 20:663-670.

39. Hoffman RM. The wayward methyl group and the cascade to cancer. Cell Cycle. 2017; 16:825-829.

40. Warburg O. On the origin of cancer cells. Science. 1956; 123:309-14.

41. Grosu AL, Weber WA, Riedel E, Jeremic B, Nieder C, Franz M, Gumprecht H, Jaeger R, Schwaiger M, Molls M. L-(methyl-11C) methionine positron emission tomography for target delineation in resected high-grade gliomas before radiotherapy. Int J Radiat Oncol Biol Phys. 2005; 63:64-74.

42. Glaudemans AW, Enting RH, Heesters MA, Dierckx RA, van Rheenen RW. Walenkamp AM, Slart RH. Value of 11C-methionine PET in imaging brain tumours and metastases. Eur J Nucl Med Mol Imaging. 2013; 40:615-635.

43. Tsuyuguchi N, Takami T, Sunada I, Iwai Y, Yamanaka K, Tanaka K, Nishikawa M, Ohata K, Torii K, Morino M, Nishio A, Hara M. Methionine positron emission tomography for differentiation of recurrent brain tumor and radiation necrosis after stereotactic radiosurgery-in malignant glioma. Ann Nucl Med. 2004; 18:291-296.

44. Nariai T, Tanaka Y, Wakimoto H, Aoyagi M, Tamaki M, Ishiwata K, Senda M, Ishii K, Hirakawa K, Ohno K. Usefulness of L-[methyl-11C] methionine-positron emission tomography as a biological monitoring tool in the treatment of glioma. J Neurosurg. 2005; 103:498-507.

45. Tamura K, Yoshikawa K, Ishikawa H, Hasebe M, Tsuji H, Yanagi T, Suzuki K, Kubo A, Tsujii H. Carbon-11methionine PET imaging of choroidal melanoma and the time course after carbon ion beam radiotherapy. Anticancer Res. 2009; 29:1507-14.

46. Singhal T, Narayanan TK, Jacobs MP, Bal C, Mantil JC. 11C-methionine PET for grading and prognostication in gliomas: a comparison study with 18F-FDG PET and contrast enhancement on MRI. J Nucl Med. 2012; 53:1709-1715.

47. Guo HY, Herrera H, Groce A, Hoffman RM. Expression of the biochemical defect of methionine dependence in fresh patient tumors in primary histoculture. Cancer Res. 1993; 53:2479-2483.

48. Blagosklonny MV. Matching targets for selective cancer therapy. Drug Discov Today. 2003; 8:1104-7.

49. Blagosklonny MV. Teratogens as anti-cancer drugs. Cell Cycle. 2005; 4:1518-21.

50. Blagosklonny MV. Treatment with inhibitors of caspases, that are substrates of drug transporters, selectively permits chemotherapy-induced apoptosis in multidrug-resistant cells but protects normal cells. Leukemia. 2001; 15:936-41.

51. Blagosklonny MV. Target for cancer therapy: proliferating cells or stem cells. Leukemia. 2006; 20:385-91.

52. Apontes $\mathrm{P}$, Leontieva OV, Demidenko $\mathrm{ZN}$, Li F, Blagosklonny MV. Exploring long-term protection of normal human fibroblasts and epithelial cells from chemotherapy in cell culture. Oncotarget. 2011; 2:222-33. https://doi. org/10.18632/oncotarget.248.

53. Blagosklonny MV. Tissue-selective therapy of cancer. Br J Cancer. 2003; 89:1147-51.

54. Slominski AT, Brożyna AA, Zmijewski MA, Jóźwicki W, Jetten AM, Mason RS, Tuckey RC, Elmets CA. Vitamin D signaling and melanoma: role of vitamin $\mathrm{D}$ and its receptors in melanoma progression and management. Lab Invest. 2017; 97:706-724.

55. Slominski AT, Brożyna AA, Skobowiat C, Zmijewski MA, Kim TK, Janjetovic Z, Oak AS, Jozwicki W, Jetten AM, Mason RS, Elmets C, Li W, Hoffman RM, Tuckey RC. On the role of classical and novel forms of vitamin $\mathrm{D}$ in mel noma progression and management. J Steroid Biochem Mol Biol. 2017 Jul 1. pii: S0960-0760(17)30164-4. https://doi. org/10.1016/j.jsbmb.2017.06.013.

56. Hoffman RM. Patient-derived orthotopic xenografts (PDOX) models of melanoma. Special Issue "Animal Models of Melanoma”, Slominski, A., Guest Editor. Intl J Mol Sci. 2017; 18:1875. 
57. Tan Y, Xu M, Tan X, Tan X, Wang X, Saikawa Y, Nagahama T, Sun X, Lenz M, Hoffman RM. Overexpression and large-scale production of recombinant L-methioninealpha- deamino-gamma-mercaptomethane-lyase for novel anticancer therapy. Protein Expr Purif. 1997; 9:233-245.
58. Sun X, Tan Y, Yang Z, Li S, Hoffman RM. A rapid HPLC method for the measurement of ultra-low plasma methionine concentrations applicable to methionine depletion therapy. Anticancer Res. 2005; 25:59-62. 